\title{
Elaboração e Validação de Material Didático para Escolha de Excipientes de Cápsulas Preparadas Magistralmente
}

\author{
Adriana Carrer Stefanini Gemeinder, ${ }^{1}$ Vanessa Casagrande, ${ }^{2}$ \\ Osni Lázaro Pinheiro²
}

\section{RESUMO}

Os excipientes são componentes fundamentais de uma preparação farmacêutica, estabilizando o princípio ativo, favorecendo sua solubilidade durante o processo de preparação e sua absorção após administração. A escolha dessas substâncias, entretanto, deve ser um processo criterioso, pois pode interferir na biodisponibilidade dos fármacos e causar efeitos colaterais. $\mathrm{O}$ objetivo deste estudo foi elaborar e validar um material educativo para auxiliar os farmacêuticos na escolha dos excipientes adequados para a preparação de cápsulas magistrais. Inicialmente foi elaborado um questionário com assertivas para definição dos temas que poderiam compor o material educativo sobre excipientes. Este questionário foi encaminhado para um grupo de juízes, constituídos por farmacêuticos com experiência na área de farmacotécnica. Pautado nas avaliações, foi elaborado o material educativo sobre excipientes, que foi novamente enviado aos juízes para validação. As avaliações dos juízes apoiaram a confecção de um material educativo sobre excipientes para preparação de cápsulas, seguindo os critérios do Sistema de Classificação Biofarmacêutica. 0 material foi validado, alcançando o índice de $70 \%$ de concordância proposto neste estudo, e as sugestões consideradas pertinentes foram incorporadas ao material educativo. Com o auxílio de um painel de especialistas da área de farmacotécnica, foi produzido um material educativo validado, contendo importantes informações para a escolha de excipientes de cápsulas preparadas magistralmente. O material educativo produzido pode representar um recurso importante para ser utilizado em atividades de formação continuada de profissionais que trabalham em farmácias de manipulação.

Palavras-chave: excipientes; cápsulas duras; incompatibilidade; classificação biofarmacêutica; material educativo.

\section{ELABORATION AND VALIDATION OF TEACHING MATERIAL FOR CHOOSING FILLERS} FROM CAPSULES MASTERFULLY PREPARED

\section{ABSTRACT}

Excipients are components fundamental components of a pharmaceutical preparation, stabilizing the active principle, favoring its solubility during the preparation process and its absorption after administration. However, the choice of these substance must be a careful process because they can interfere in the bioavailability of drugs and cause side effects. The objective of this study was to elaborate and validate an educational material to assist pharmacists in choosing the appropriate excipients for the preparation of magistral capsules. This questionnaire was sent to a group of judges, consisting of pharmacists with experience in area of pharmacotechnics. Based on the evaluations, the educational material on excipients was prepared and sent back to the judges for validation. The evaluations of the judges supported the preparation of educational material on excipients for the preparation of capsules following the criteria of the Biopharmaceutical Classification System. The material was validated, reaching the $70 \%$ concordance rate proposed in this study, and the suggestions considered pertinent were incorporated into the educational material. With the help of a panel of specialists in area of pharmacotechnics, a validated educational material was produced, containing important information for the choice of capsule excipients prepared masterfully. The educational material produced can represent an important resource to be used in continuing education activities for professionals working in manipulation pharmacies.

Keywords: excipients; hard capsules; incompatibility; biopharmaceutical classification; didactic material.

RECEBIDO EM: 16/2/2020

MODIFICAÇÕES SOLICITADAS EM: 9/6/2020

ACEITO EM: 6/7/2020

\footnotetext{
${ }_{1}^{1}$ Autora correspondente. Faculdade de Medicina de Marília. R. Monte Carmelo, 800 - Fragata. Marília/SP, Brasil. CEP 17519030. http://lattes.cnpq.br/9776997502548521. https://orcid.org/0000-0001-5656-5527. adrianastefanini.01@gmail.com

2 Faculdade de Medicina de Marília. Marília/SP, Brasil.
} 


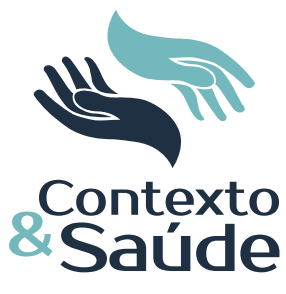

\section{INTRODUÇÃO}

Em relatório produzido pela Associação Nacional dos Farmacêuticos Magistrais (Anfarmag), foi demonstrado um crescimento de $8,8 \%$ no setor das farmácias de manipulação de medicamentos entre os anos de 2014 e 2018, mesmo com a economia estando em desaceleração neste período. No Brasil, o aumento pela procura destes produtos tem provocado grandes mudanças no setor, tanto na qualidade dos insumos e nos produtos acabados quanto nas exigências por parte da legislação vigente (CUPERTINO; SILVA; SOUZA, 2017; ANFARMAG, 2018).

Além de proporcionar menor custo do medicamento, a farmácia de manipulação é considerada um complemento da indústria farmacêutica. A produção de medicamentos individualizados é o seu principal propósito, ou seja, o preparo de medicamentos em concentrações que não podem ser encontradas em formulações industrializadas, assim como formas farmacêuticas adequadas para pacientes cujo estado clínico requer alguma particularidade (RUMEL; NISHIOKA; SANTOS, 2006).

Nesse contexto, as formas farmacêuticas sólidas orais, como é o caso das cápsulas magistrais, são bastante prescritas atualmente, não apenas em decorrência do custo reduzido, mas, principalmente, por oferecerem ao prescritor a flexibilidade de dosagem e individualização da posologia para o paciente (VASCONCELOS; CANGUSSI; MESQUITA, 2016).

Essas preparações geralmente são desenvolvidas para uma liberação imediata no organismo, porém, nas cápsulas, para que ocorra uma absorção completa, é necessário que o fármaco esteja adequadamente solubilizado de modo a garantir a segurança e eficácia terapêutica (VAN DER MERWE; STEENEKAMP; STEYN, 2020).

A eficácia terapêutica das preparações farmacêuticas sólidas depende da biodisponibilidade dos princípios ativos presentes nesses medicamentos, sendo importante destacar que esse parâmetro farmacocinético sofre uma direta influência da solubilidade e permeabilidade dos fármacos envolvidos (SILVA; LIMA; CRUZ, 2018; VAN DER MERWE; STEENEKAMP; STEYN, 2020).

Com o intuito de identificar os fármacos em relação a sua potencial biodisponibilidade, foi criado, em 1995, o Sistema de Classificação Biofarmacêutica (SCB), que classifica os princípios ativos em quatro classes de acordo com a taxa e extensão de absorção de uma forma farmacêutica de liberação imediata. Os critérios utilizados para essa classificação envolvem a solubilidade em água em determinada faixa fisiológica de $\mathrm{pH}$ e também a sua permeabilidade em membranas entéricas (BOU-CHACRA et al., 2017).

Os fármacos da classe I são amplamente absorvidos, portanto não existe necessidade da utilização de adjuvantes que melhorem a solubilidade e a permeabilidade. Por sua vez, os fármacos da classe III possuem alta solubilidade e baixa permeabilidade, não sendo possível alterações com o uso de excipientes. Em contrapartida, os fármacos das classes II, com alta permeabilidade e baixa solubilidade, e IV, com baixa permeabilidade e solubilidade, necessitam de adjuvantes especiais. Dessa maneira, em decorrência das suas propriedades biofarmacêu- 
ticas, necessitam percorrer todo o TGI para que sejam absorvidos, fazendo com que a absorção ocorra de maneira incompleta, uma vez que é dependente do tempo gasto nesse percurso (FLANAGAN, 2019; JONES; PARROTT; OHLENBUSCH, 2006).

O SCB mostra que as substâncias adjuvantes possuem um papel muito importante no preparo de um composto magistral, pois podem interferir na biodisponibilidade de um fármaco. Dessa forma, para a produção de um composto magistral de boa qualidade, a preocupação não reside unicamente na escolha do princípio ativo e nos cuidados técnicos durante a manipulação, mas também inclui a escolha dos excipientes adequados para cada formulação (REKER; BLUM; STEIGER, 2019).

No início da produção dos medicamentos magistrais, os excipientes eram descritos como substâncias inertes que eram adicionadas às preparações farmacêuticas, com o objetivo de viabilizar a sua administração; portanto a preocupação residia em características como volume, formato e sabor. Atualmente o conceito de excipiente farmacêutico é mais amplo, não se restringindo a uma substância que simplesmente completa o volume de uma formulação, mas, ao invés disso, favorece a estabilidade da preparação e auxilia na absorção do princípio ativo (ABRANTES; DUARTE; REIS, 2016).

Dependendo da preparação farmacêutica, os excipientes podem assumir funções solubilizantes, diluentes, lubrificantes, suspensores, desagregantes ou desintegrantes, flavorizantes, conservantes, modificantes de liberação de fármacos, molhantes e formadores de filmes (NASCIMENTO; SANTANA; SILVA JUNIOR, 2019).

Além destas funções, auxiliando na estabilização dos fármacos, melhorando suas propriedades organolépticas e interferindo na sua biodisponibilidade, os excipientes também podem causar efeitos adversos, os quais, geralmente, de maneira equivocada, são atribuídos exclusivamente ao princípio ativo do medicamento (REKER; BLUM; STEIGER, 2019).

Dessa forma, os excipientes podem causar ações indesejadas, como é o caso de manifestações alérgicas caracterizadas por urticária, angioedema, broncoespasmo e anafilaxia. Além disto, também é possível identificar intolerância dos pacientes aos excipientes, com a manifestação de sintomas gastrointestinais por mecanismos relacionados aos efeitos osmóticos dessas substâncias ou por processos decorrentes de sua fermentação no sistema digestivo (REKER; BLUM; STEIGER, 2019).

Os dados apresentados até o presente momento mostram que o conceito de excipiente, associado a uma substância inerte, não condiz com o importante papel desses adjuvantes em uma preparação farmacêutica.

Associado a isso, pesquisa realizada por meio de questionário que abordava a preparação de cápsulas de medicamentos que requerem cuidados especiais na definição dos excipientes, mostrou que se faz necessário um melhor preparo das farmácias magistrais, pois os profissionais participantes apresentaram um baixo índice de acerto na escolha dos excipientes, fator que comprome-

Editora Unijuí - Revista Contexto \& Saúde - ISSN 2176-7114 - v. 21, n. 43, jul./set. 2021 
teria a qualidade, eficácia e segurança dos medicamentos abordados no estudo (AMARAL; FEDERECI; SANT'ANA, 2016).

Dessa maneira, seja pelo aumento da biodisponibilidade dos fármacos ou mesmo pelo potencial que essas substâncias possuem no desencadeamento de reações adversas, a escolha dos excipientes adequados para compor uma formulação é um aspecto importante na terapêutica medicamentosa.

A elaboração de materiais instrucionais com enfoque no papel dos excipientes em uma preparação magistral, validado por um painel de juízes com expertise na área de manipulação de formas farmacêuticas sólidas, poderá auxiliar os profissionais que manipulam as preparações magistrais. Este material deverá enfocar a importância da escolha criteriosa dos excipientes de um medicamento magistral, pois esses compostos não são substâncias inertes e, portanto, suas potencialidades, seja para alterar a ação do fármaco, ou mesmo desencadear efeitos adversos, devem ser consideradas.

A literatura destaca uma diversidade de estudos que envolvem a validação de materiais educativos na área da saúde, entretanto não se registra a existência de materiais destinados a auxiliar os profissionais na escolha dos excipientes mais adequados para as preparações magistrais.

Dessa maneira, o objetivo deste estudo foi elaborar e validar um material educativo para auxiliar os farmacêuticos na escolha dos excipientes adequados para a preparação de cápsulas magistrais.

\section{MATERIAL E MÉTODOS}

O presente projeto foi aprovado pelo Comitê de Ética em Pesquisa Envolvendo Seres Humanos (CEP), com o Certificado de Apresentação para Apreciação Ética (CAAE) no 03947818.7.0000.5413, e aprovado sob o parecer número 3.094.441. O trabalho foi dividido em três fases, sendo a primeira relacionada à definição dos temas, seguida pela confecção e validação do material educativo.

Para definição dos temas que compuseram o material educativo, foi realizado um levantamento nas bases de dados Bireme, PubMed e Scielo, utilizando os seguintes descritores: excipientes, cápsulas duras, incompatibilidade, Sistema de Classificação Biofarmacêutica e material educativo.

Após o levantamento de dados na literatura, foi construído um questionário contendo assertivas sobre os temas que deveriam compor o material educativo. O SCB norteou a confecção das assertivas do questionário, posto que estas diretrizes relacionam importantes fatores para absorção dos fármacos, no caso a solubilidade e permeabilidade (FLANAGAN, 2019).

Em seguida, o questionário foi enviado para o grupo de juízes especialistas com o objetivo de validar a proposta inicial dos temas sobre a escolha dos excipientes para preparações de cápsulas magistrais duras. A amostra deste estudo foi, inicialmente, idealizada para obtenção de um grupo de dez juízes, representados por farmacêuticos com experiência na área farmacotécnica e titulação mínima de mestre.

Editora Unijuí - Revista Contexto \& Saúde - ISSN 2176-7114 - v. 21, n. 43, jul./set. 2021 
Os juízes foram convidados a participar desta etapa do estudo por e-mail. Após a confirmação da disponibilidade para participar do estudo, esses profissionais receberam um link, disponibilizado no Google forms ${ }^{\circ}$, que, inicialmente, apresentava uma carta convite explicando o objetivo do trabalho e, em seguida, disponibilizava uma ficha de preenchimento para caracterização dos juízes.

Na sequência, o juiz acessava o instrumento utilizado na validação dos temas do material educativo. Cada assertiva foi seguida de uma escala do tipo Likert com quatro pontos: discordo totalmente (DT), discordo (D), concordo (C) e concordo totalmente (CT) e um campo aberto no qual os participantes puderam expressar livremente suas opiniões sobre o tema proposto.

Após a análise de todas as avaliações dos juízes, foi confeccionada a primeira versão do material educativo, com o apoio de um profissional da área de Design Gráfico, que utilizou ferramentas do software Photoshop $\mathrm{CC}^{\circ}$. O material foi elaborado buscando-se uma modernização da linguagem escrita e visual para obtenção de um produto com uma mensagem clara, bastante didática e com um design funcional. Tendo em vista tratar-se de material destinado a profissionais com formação superior, a linguagem utilizada foi de natureza técnica. A escrita do material teve como base principal na sua composição a família tipográfica Gotham, sem serifa, com base e ângulos retos, com uso de Kerning para ajuste do espaçamento entre letras.

Uma vez finalizada a versão preliminar, o material educativo foi enviado de maneira eletrônica para os juízes que participaram da primeira fase deste estudo. Também foi enviado um instrumento de avaliação contendo assertivas, seguidas de uma escala do tipo Likert e um campo aberto para considerações. Este instrumento de avaliação foi adaptado e disponibilizado mediante um formulário digital na Plataforma Google forms ${ }^{\circ}$, acessado pelos juízes por meio de um link de acesso, que foi enviado por e-mail junto com o material educativo.

Para a definição dos temas abordados na composição do material educativo e também na validação do conteúdo, linguagem, ilustrações, layout, motivação e cultura, foi utilizado o cálculo da frequência percentual de concordância entre os juízes de acordo com a fórmula descrita a seguir:

$$
\% \text { de Concordância }=\frac{\text { Número de juízes que concordaram }}{\text { Número total de juízes }} \times 100
$$

Os itens foram considerados validados quando a porcentagem de concordância entre os juízes especialistas atingiu minimamente 70\% (BRACCIALLI; BRACCIALLI; AUDI, 2019).

Os conteúdos presentes no campo "comentários adicionais" foram analisados e as sugestões consideradas pertinentes foram incorporadas ao material educativo.

\section{RESULTADOS E DISCUSSÃO}

Dentre os dez juízes convidados para colaborar na fase inicial da elaboração do material educativo, sete (70\%) responderam à avaliação das assertivas para a escolha dos temas que poderiam compor o material educativo (J1 a J7 - Quadro 1).

Editora Unijuí - Revista Contexto \& Saúde - ISSN 2176-7114 - v. 21, n. 43, jul./set. 2021 
Para a etapa de validação da primeira versão do material educativo foram contactados os mesmos dez juízes convidados inicialmente, entretanto apenas cinco (J2, J3, J4, J5 e J6) aceitaram participar da avaliação do material educativo, portanto foram convidados dois novos juízes (J8 e J9) exclusivamente para validação do material educativo (Quadro 1).

Os juízes participantes deste estudo apresentaram idade entre 32 e 59 anos e experiência na área entre 6 e 30 anos, conforme observado no Quadro 1.

Quadro 1 - Caracterização dos juízes participantes da fase inicial $(n=7)$

\begin{tabular}{|c|c|c|c|c|}
\hline JUÍZ & $\begin{array}{c}\text { IDADE } \\
\text { (Anos) }\end{array}$ & $\begin{array}{c}\text { EXPERIÊNCIA } \\
\text { (Anos) }\end{array}$ & TITULAÇÃo & ÁREA DE ATUAÇÃo \\
\hline $\mathbf{1}$ & 56 & 22 & Mestre & Manipulação de Produtos Naturais \\
\hline $\mathbf{2}$ & 39 & 17 & Livre-Docente & $\begin{array}{c}\text { Docência em Ensino Superior e Pes- } \\
\text { quisa - Tecnologia Farmacêutica }\end{array}$ \\
\hline $\mathbf{3}$ & 38 & 07 & Pós-Doutorado & $\begin{array}{c}\text { Docência em Ensino Superior e Pes- } \\
\text { quisa - Tecnologia Farmacêutica }\end{array}$ \\
\hline $\mathbf{4}$ & 32 & 09 & Mestre & Farmacotécnica \\
\hline $\mathbf{5}$ & 59 & 30 & Mestre & Farmácia de Manipulação \\
\hline $\mathbf{6}$ & 51 & 28 & Mestre & Docência em Ensino Superior \\
\hline $\mathbf{7}$ & 36 & 06 & Pós-Doutorado & Farmacotécnica \\
\hline $\mathbf{8}$ & 40 & 10 & Mestre & Docência em Ensino Superior \\
\hline $\mathbf{9}$ & 32 & 8 & Mestre & Farmacêutica \\
\hline
\end{tabular}

Fonte: Elaborado pelos autores.

Após análises das respostas apresentadas pelos juízes em relação aos temas que deveriam compor o material educativo, foi verificado que houve nível de concordância acima de $80 \%$ em todas as assertivas, portanto dentro dos limites estabelecidos neste estudo.

De acordo com a avaliação dos juízes, a versão inicial do material educativo deveria apresentar ilustrações e contemplar a importância dos excipientes, os usos equivocados e incompatibilidades destes agentes, assim como os efeitos adversos e o Sistema de Classificação Biofarmacêutica (SCB) (Tabela 1).

Tabela 1 - Índice de concordância dos juízes em relação aos temas propostos para compor o material educativo $(n=7)$

\begin{tabular}{|c|c|}
\hline ASSERTIVAS & IC (\%) \\
\hline S. & 100 \\
\hline $\begin{array}{l}\text { eve informar as consequências de se utilizar de forma } \\
\text { es". }\end{array}$ & 100 \\
\hline informar incomnatibilidadec & 100 \\
\hline $\begin{array}{l}\text { deve destacar efeitos adversos que podem ocorrer em } \\
\text { sincráticos. }\end{array}$ & 85, \\
\hline O material educativo deve explicar sobre o Sistema de Classificação Biofar- & 100 \\
\hline O material educativo deve destacar as Classes do Sistema de Cla & \\
\hline
\end{tabular}

Editora Unijuí - Revista Contexto \& Saúde - ISSN 2176-7114 - v. 21, n. 43, jul./set. 2021 
7. O material educativo deve destacar particularidades das classes II e IV do SCB, escolhidas para este estudo.

8. O material educativo deve orientar qual a melhor escolha de "Excipientes" das classes II e IV do SCB.

Embora as assertivas 4 e 6 tenham apresentado divergências entre os avaliadores, ambas atingiram o percentual de concordância estabelecido neste estudo, de modo que os efeitos adversos dos excipientes e o Sistema de Classificação Biofarmacêutica foram contemplados na versão inicial do material educativo.

Os juízes também utilizaram o campo aberto do instrumento e fizeram sugestões para a elaboração do material educativo (Quadro 2).

Quadro 2 - Sugestões dos juízes em relação aos temas que devem ser contemplados no material educativo

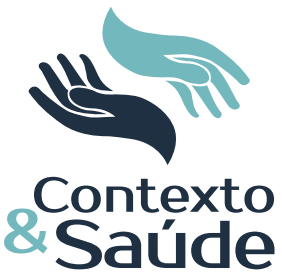

\section{ASSERTIVAS/SUGESTÕES}

O material educativo deve destacar efeitos adversos que podem ocorrer em razão de sintomas idiossincráticos.

Sugestões: Efeitos adversos não ocorrem em decorrência de sintomas (J3).

O material educativo deve explicar sobre o Sistema de Classificação Biofarmacêutica (SCB).

Sugestões: Essencial (J7).

O material educativo deve destacar particularidades das classes II e IV do SCB, escolhidas para este estudo.

Sugestões: Deve destacar as particularidades de todas as classes (J7).

O material educativo deve conter ilustrações informativas.

Sugestões: Porém as ilustrações devem ser bastante claras e autoexplicativas para não confundir o estudante. (J7).

Fonte: Elaborado pelos autores.

De uma maneira geral as sugestões realizadas pelos juízes nos campos abertos do instrumento respaldaram a construção de um material educativo abordando as classes II e IV do Sistema de Classificação Biofarmacêutica, ainda que um dos juízes (J7) tenha mencionado a importância de destacar as particularidades de todas as classes.

A concepção inicial do presente estudo em abordar apenas as classes II e IV é decorrente, principalmente, da baixa solubilidade dos fármacos desses grupos, pois esse aspecto está diretamente relacionado à taxa de absorção. A escolha dos excipientes adequados para os fármacos desses grupos poderá meIhorar a taxa de absorção dos princípios ativos presentes nessas preparações (FLANAGAN, 2019).

Em relação aos fármacos da classe I, cabe destacar que se tratam de moléculas geralmente amplamente absorvidas, não existindo necessidade da utilização de adjuvantes que melhorem a sua solubilidade e a permeabilidade. Por sua vez, os fármacos da classe III já possuem alta solubilidade, porém o que interfere

Editora Unijuí - Revista Contexto \& Saúde - ISSN 2176-7114 - v. 21, n. 43, jul./set. 2021 
na taxa de absorção é a baixa permeabilidade destes compostos, mas isso geralmente não é possível ser alterado com o uso de excipientes (BOU-CHACRA et al., 2017; FLANAGAN, 2019).

Os efeitos adversos mais frequentes e também aqueles idiossincráticos, decorrentes do uso dos excipientes nas formulações, também estão sendo contemplados na primeira versão do material educativo. A abordagem dos efeitos adversos, decorrentes do uso dos excipientes, é importante, pois estudos mostram que, muitas vezes, são os excipientes e não os princípios ativos das formulações os responsáveis pelos efeitos adversos. Cabe destacar que alguns destes efeitos adversos são decorrentes de fatores idiossincráticos, como é o caso da lactose em pacientes intolerantes a este açúcar (SILVA; LÖBENBERG; DAVIES, 2018, VILLANOVA; SÁ, 2009).

Em relação às ilustrações do material educativo, é importante mencionar que foram feitas com o cuidado de se apresentarem claras e autoexplicativas, conforme apontado em uma das avaliações (J7). Cabe destacar que as ilustrações devem apresentar-se sem nenhum tipo de distração, cuja função é atrair o leitor, despertar e manter o interesse do profissional pela leitura (CORDEIRO; LOPES; LIRA, 2017).

As avaliações dos especialistas referentes ao conteúdo, linguagem, ilustrações, layout, motivação e cultura, estão apresentados na Tabela 2.

Tabela 2 - Índice de concordância (IC) dos juízes em relação ao conteúdo, linguagem e ilustrações do material educativo $(n=7)$

\begin{tabular}{lc}
\hline \multicolumn{1}{c}{ Itens Avaliados } & IC (\%) \\
\hline Conteúdo & \\
$\begin{array}{l}\text { O conteúdo está apropriado ao público-alvo (profissionais que atuam em far- } \\
\text { mácias de manipulação). }\end{array}$ & 100 \\
$\begin{array}{l}\text { A divisão dos títulos e subtítulos do material são pertinentes. } \\
\text { Os trechos-chave (trechos em destaque) são pontos importantes e merecem } \\
\text { destaque. }\end{array}$ & 100 \\
$\begin{array}{l}\text { O conteúdo é suficiente para atender às necessidades do público-alvo (profis- } \\
\text { sionais que atuam em farmácias de manipulação). }\end{array}$ & 71,5 \\
$\begin{array}{l}\text { Linguagem } \\
\text { O estilo da redação é compatível com o público-alvo (profissionais que atuam } \\
\text { em farmácias de manipulação). }\end{array}$ & 100 \\
$\begin{array}{l}\text { A escrita utilizada é atrativa. } \\
\text { A linguagem é clara e objetiva. }\end{array}$ & 100 \\
$\begin{array}{l}\text { llustrações } \\
\text { As ilustrações utilizadas são pertinentes com o conteúdo do material e escla- } \\
\text { recem o conteúdo. }\end{array}$ & 100 \\
$\begin{array}{l}\text { As ilustrações são claras e transmitem facilidade de compreensão. } \\
\text { As legendas das imagens são adequadas e auxiliam o leitor a compreender a } \\
\text { imagem. }\end{array}$ & 81,5 \\
$\begin{array}{l}\text { A quantidade de ilustrações está adequada para o conteúdo do material edu- } \\
\text { cativo. }\end{array}$ & 85,7 \\
$\begin{array}{l}\text { Layout } \\
\text { O tipo de letra utilizado facilita a leitura. }\end{array}$ & 100 \\
$\begin{array}{l}\text { As cores aplicadas ao texto são pertinentes e facilitadoras para a leitura. } \\
\end{array}$ & 100
\end{tabular}

Editora Unijuí - Revista Contexto \& Saúde - ISSN 2176-7114 - v. 21, n. 43, jul./set. 2021 
A composição visual está atrativa e bem-organizada.

O formato (tamanho) do material educativo e o número de páginas estão adequados.

O tamanho das letras dos títulos, subtítulos e textos estão adequados.

\section{Motivação}

O conteúdo está motivador e incentiva a prosseguir com a leitura.

O conteúdo despertou interesse no leitor.

O conteúdo atende às dúvidas mais comuns dos profissionais que atuam em farmácias de manipulação.

\section{Cultura}

O texto está compatível com o público-alvo (profissionais que atuam em farmácias de manipulação) atendendo aos diferentes níveis de conhecimento.

Legenda: IC - Índice de concordância.

Fonte: Adaptada de SOUSA; TURRINI, 2012.

Observa-se que, de acordo com os critérios adotados, foi atingido um índice de concordância acima de $70 \%$ entre os juízes, portanto houve validação do material educativo produzido para auxiliar na escolha de excipientes de cápsulas preparadas magistralmente.

Um dos aspectos de discordância entre os juízes refere-se às ilustrações, entretanto cabe destacar que as figuras ou imagens utilizadas na elaboração do material educativo têm um escopo mais ilustrativo do que informativo, com o objetivo de proporcionar uma leitura mais dinâmica e agradável. Um exemplo disto pode ser observado na Figura 1, que mostra a página de apresentação do material educativo.

Figura 1 - Exemplo do papel das ilustrações no material educativo "Como escolher excipientes para cápsulas preparadas magistralmente"

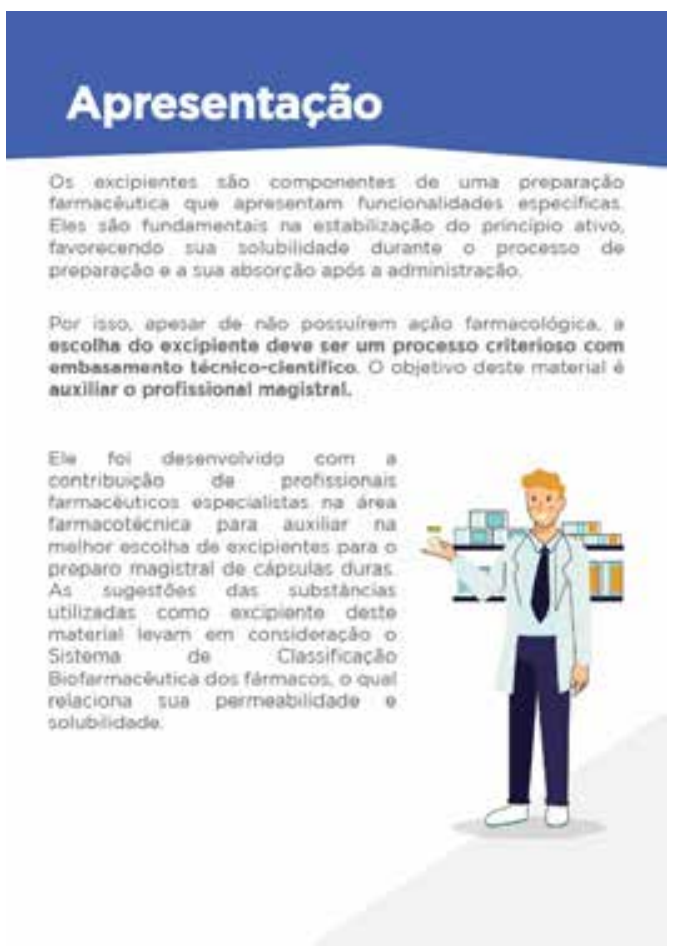

Fonte: Elaborada pelos autores. 
Alguns juízes utilizaram o espaço de comentários adicionais para expor suas sugestões ou indicar suas discordâncias a respeito do material educativo (Quadro 4).

Quadro 4 - Comentários adicionais dos juízes às assertivas referentes à validação do material educativo

\begin{tabular}{|c|}
\hline COMENTÁRIOS ADICIONAIS \\
\hline $\begin{array}{l}\text { Sugiro incluir uma lista de substituições possíveis, bem como uma relação de incompa- } \\
\text { tibilidades (J2). }\end{array}$ \\
\hline $\begin{array}{l}\text { Têm informações conceitualmente inapropriadas, como dizer que um excipiente só } \\
\text { atrapalha a dissolução ou biodisponibilidade, que diluente serve para aumentar solu- } \\
\text { bilidade, que tem excipiente que auxilia na desintegração, mas o guia é de cápsulas... é } \\
\text { necessário revisar (J3). }\end{array}$ \\
\hline $\begin{array}{l}\text { Apenas uma observação: nos principais excipientes utilizados deveria dar também ên- } \\
\text { fase ao amido de milho e não só ao amido glicolato de sódio, que é utilizado mais na } \\
\text { indústria farmacêutica como desintegrante. O Amido é mais acessível, barato, pode-se } \\
\text { utilizar em grande quantidade, inerte (embora tenha problemas de conservação com a } \\
\text { umidade, contamina-se facilmente, mas isso pode ser eliminado associando-se ao ae- } \\
\text { rosil). Talvez o maior problema que temos hoje em dia nas farmácias de manipulação é } \\
\text { utilizar excipientes sem critério nenhum; é achar que pelo fato do excipiente ser inerte, } \\
\text { ele não vai mudar em nada a ação do ativo, e aí que vem os problemas que fazem com } \\
\text { que os médicos não indiquem medicamentos manipulados. Mais iniciativas como essa } \\
\text { precisam ser feitas para que tenhamos, cada vez mais, profissionais farmacêuticos qua- } \\
\text { lificados no mercado de trabalho, profissionais que garantam 100\% de qualidade no seu } \\
\text { produto, e quem ganha com isso é o consumidor desse medicamento (J5). }\end{array}$ \\
\hline Proposta excelente! (J6). \\
\hline cas \\
\hline
\end{tabular}

Fonte: Elaborado pelos autores.

Dentre as avaliações, foi solicitado que o material educativo "desse mais ênfase ao amido de milho e não só ao amido glicolato de sódio, que é utilizado mais na indústria farmacêutica como desintegrante" (J5). Trata-se de uma sugestão coerente, pois o amido de milho tem um baixo custo e boa compatibilidade (VILLANOVA; SÁ, 2009). Este apontamento foi incluído na versão final do material educativo.

O mesmo avaliador apoiou integralmente a premissa trazida por este estudo, de que os profissionais que atuam na área de manipulação de medicamentos magistrais muitas vezes não atribuem a importância devida aos excipientes. De acordo com o juiz, um problema nas farmácias de manipulação é utilizar excipientes sem critérios, justamente por considerar que estes adjuvantes sejam inertes e que não alterem a ação do fármaco. Este juiz destacou, também, que isso pode ser um dos motivos pelos quais alguns médicos não indiquem medicamentos manipulados.

Apesar de os excipientes serem farmacologicamente inertes, a lactose, quando utilizada como agente diluente, pode aumentar a solubilidade do fármaco, provocando, consequentemente, intoxicação pelo aumento da absorção. Outro aspecto importante é que o uso do amido de trigo, mesmo em doses baixas,

Editora Unijuí - Revista Contexto \& Saúde - ISSN 2176-7114 - v. 21, n. 43, jul./set. 2021 
mas utilizado de maneira crônica, pode provocar reações severas em pacientes que sofrem de doença celíaca (REKER; BLUM; STEIGER, 2019; SILVA; LÖBENBERG; DAVIES, 2018).

Pressupondo que os excipientes muitas vezes não são escolhidos de maneira criteriosa nas farmácias de manipulação, um dos juízes reconheceu a importância de produção de materiais educativos sobre essa temática: "Mais iniciativas como essa precisam ser feitas para que tenhamos, cada vez mais, profissionais farmacêuticos qualificados no mercado de trabalho, profissionais que garantam $100 \%$ de qualidade no seu produto, e quem ganha com isso é o consumidor desse medicamento" (J5).

Cabe destacar que os excipientes geralmente constituem a maior parte das formas farmacêuticas sólidas, como cápsulas e comprimidos, representando aproximadamente $60 \%$ da massa destas preparações. Nesse contexto também deve ser considerada a possibilidade do uso de polifarmácia, principalmente em pessoas idosas, gerando o consumo de uma quantidade significativa de excipientes (REKER; BLUM; STEIGER, 2019).

Por outro lado, os avaliadores também fizeram questionamentos em relação a alguns conteúdos específicos do material educativo. Um desses questionamentos refere-se à percepção do especialista (J3) de que o material educativo trouxe a concepção de que o excipiente somente prejudica a dissolução e a biodisponibilidade. Na página de apresentação do material educativo (Figura 1), entretanto, foi feita a justificativa da importância do excipiente na forma farmacêutica com a informação "...fundamentais na estabilização do princípio ativo, favorecendo sua solubilidade durante o processo de preparação e a sua absorção após a administração".

Também foi sugerido que o conteúdo deveria ser revisado, uma vez que os excipientes podem ser empregados para várias finalidades. Tendo em vista esse apontamento, algumas informações foram alteradas dando um melhor entendimento em relação à proposta.

Quanto ao papel do diluente, na versão final do material o trecho sobre a dissolução dos fármacos destacou que os excipientes "podem favorecer a velocidade de dissolução dos fármacos...", de modo a atender a sugestões do avaliador.

Os diluentes representam um dos principais excipientes utilizados no preparo de cápsulas, sendo adicionados à formulação para completar a massa necessária para a forma farmacêutica. Em razão, entretanto, das suas características hidrofilicas, podem melhorar a velocidade de dissolução dos fármacos pouco solúveis, pois aumentam a superfície de contato do conteúdo encapsulado (VAN DER MERWE; STEENEKAMP; STEYN, 2020).

Outro aspecto mencionado pelo juiz J3 diz respeito ao termo "desintegrante", que, na versão final do material educativo, foi substituído por "desagregante". Apesar de terem sido realizadas as alterações, cabe destacar que estes termos podem estar ligados a preferências pessoais de escrita, uma vez que, literalmente, apresentam o mesmo significado, e diferentes autores apontam o uso do termo "desintegrante" para excipientes utilizados no preparo de cápsulas,

Editora Unijuí - Revista Contexto \& Saúde - ISSN 2176-7114 - v. 21, n. 43, jul./set. 2021 
pois sua função é auxiliar na desagregação do conteúdo das cápsulas após sua administração (FERREIRA, 2019; VILLANOVA; SÁ, 2009).

Um dos especialistas (J2) sugeriu que o material educativo deveria descrever as incompatibilidades dos excipientes e as opções indicadas nessas circunstâncias. Cabe destacar que o material traz as principais incompatibilidades dos excipientes mais utilizados no preparo de cápsulas, bem como as concentrações e diferentes indicações de um mesmo excipiente.

Nesse sentido, nas páginas 9 a 12 do material educativo pode-se observar a descrição de diferentes substâncias que são indicadas com a mesma funcionalidade (Figura 2). Como exemplo de agente diluente, verifica-se o amido de milho na concentração de 5,0 - 75,0\% e a celulose microcristalina na concentração de $20 \%$ - 90\%, e, ainda, suas incompatibilidades. Observa-se, também, o dióxido de silício coloidal indicado como agente lubrificante na concentração de $0,1-0,5 \%$, assim como a celulose microcristalina na concentração de $5,0-20 \%$.

Figura 2 - Excipientes mais utilizados para preparo de cápsulas, destacados no material educativo "Como escolher excipientes para cápsulas preparadas magistralmente"

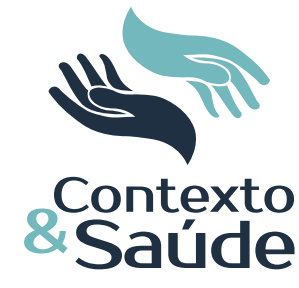

\section{Excipientes mais utilizados}

AMIDO DE MILHO: Empregado como DILUENTE

(Concentracbo usual: $5,0-75,0 \%$ ), usar ansociado ao dióvido

de slicicio coloidal. Por ser um diluente hidrofilico, facillata a colubilidade de tármacos pouco soluveis e tavorece a

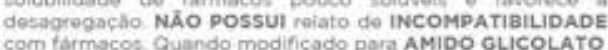
OE sóblo adquiro caracteristicas DESAGREGANTES Concentraçión usuat $5,0-10,0 \%$ ) o possu INCOMPATIBIUDADE com ácido asé́rbico.

\section{Excipientes mais utilizados}

CELULOSE MICROCRISTALINA: USado COMO DILUENTE (Concentraçōo usualt $20,0-90,0 \%$ ), LUBRIFICANTE
(Concentraço utual: $5,0-20,0 \%$ ), DESAGREGANTE

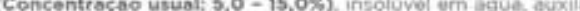
ha desagregacho dis formia farmsceutica sem interferit no tolubilidade do farmaco. INCOMPATIBILIDADE; com agente: oxidarites fortes

DIOXIDO DE SILICIO COLOIDAL (A.ROSIIV): ABSORVENTE LUQRIFICANTE (concentraç̄o uausl: $0,1-0,5 \%$ ), facititador umidado: Nao postui rolato do INCOMPATIBILIDADE.

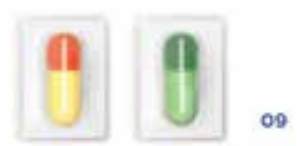

ESTEARATO DE MAGNESIO: USAdO COMO LUBRIFICANTE (Concentraçà uaval: $0,25-5,0 \%$ ) Sendo um composto

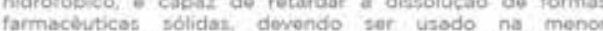
concentraça posstivel o associado à um agente tensoativo (lauril sultato de sodio) para facilitar a molhaperm da mistura nos fluidos gastrointertinais. INCOMPATIBILIDADE: com dcido acotilsalicilico algumas vitaminas e rais cie forto

FOSFATO DE CÁLCIO DIBÁsICO: Pode tor a funclo de DILUENTE O TAMPONANTE, mouer a ediclo de agente DILUENTE - TAMPONANTE, maner a adicho de agente INCOMPATIBILIOADE: coen derivados da tetracictina. cofaloxints promovido pelo forfato do callcio dibartico 09 


\section{Excipientes mais utilizados}

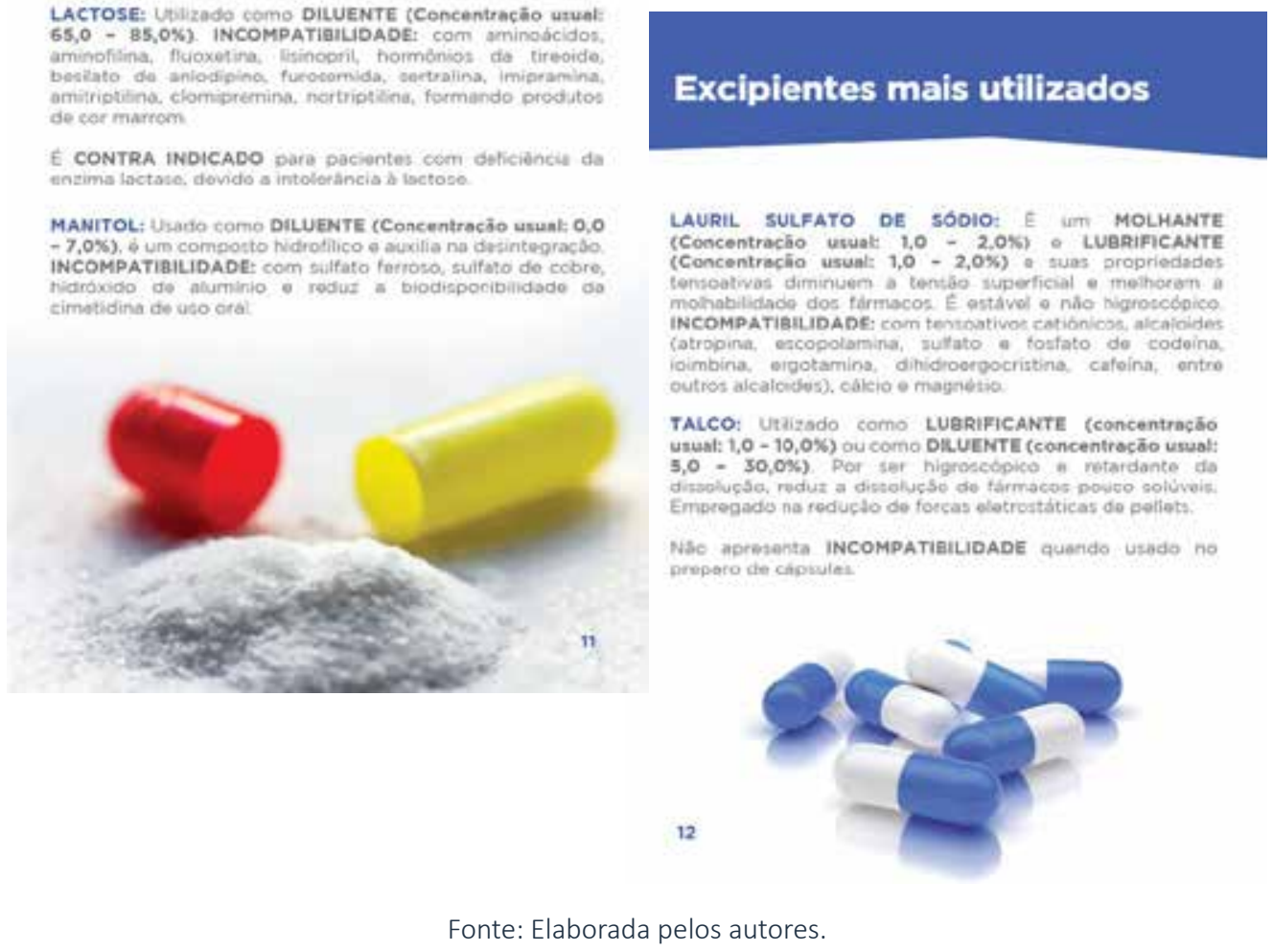

Após a análise e incorporação das sugestões realizadas pelos juízes, a versão final do material educativo apresentou 21 páginas e 16 ilustrações.

\section{CONSIDERAÇÕES FINAIS}

O medicamento magistral pode representar a única alternativa de tratamento para o paciente, por possibilitar a associação de diferentes substâncias ativas em doses específicas, e também permitir a escolha da forma farmacêutica. Por outro lado, no preparo de cápsulas magistrais a escolha equivocada dos excipientes pode contribuir para instabilidades na formulação e reações indesejadas aos pacientes, podendo comprometer, de maneira significativa, o tratamento.

Dessa maneira, é fundamental que o farmacêutico magistral busque qualificação profissional de forma contínua, e, principalmente, conhecimento sobre as substâncias ativas e suas possíveis interações com outras substâncias adjuvantes de uma formulação.

Pautado nessas necessidades, o presente estudo possibilitou a elaboração e validação de um material educativo com importantes informações para a escoIha de excipientes de cápsulas preparadas magistralmente.

O material educativo, produzido neste estudo, pode representar um recurso importante tanto para a autoinstrução quanto para a utilização em atividades de educação continuada de profissionais que trabalham em farmácias de mani- 
pulação. Estas ações poderão dar subsídios para melhorar a qualidade farmacotécnica dos produtos magistrais na forma de cápsulas, e, com isso, aumentar a segurança dos pacientes que fazem uso destes produtos.

\section{REFERÊNCIAS}

ABRANTES, C. G.; DUARTE, D.; REIS, C. P. An overview of pharmaceutical excipients: safe or not safe? Journal of Pharmaceutical Sciences, v. 105, n. 7, p. 2.019-2.026, 2016.

AMARAL, P. A.; FEDERECI, M. R.; SANT'ANA, J. L. U. C. Análise de excipientes utilizados em cápsulas preparadas em farmácias magistrais. Revista Brasileira Multidisciplinar, v. 19, n. 1, p. 24-30, 2016.

ANFARMAG. Associação Nacional de Farmacêuticos Magistrais. Panorama setorial. São Paulo: Melting Color, 2018.

BOU-CHACRA, N. et al. Evolution of choice os solubility and dissolution media after two decades of Biopharmaceutical Classification System. The American Association of Pharmaceutical Scientists Journal, v. 19, n. 4, p. 989-1.001, 2017.

BRACCIALLI, L. M. P.; BRACCIALLI, A. C.; AUDI, M. Translation and Cultural Adaptation of Instruments to Assess the Predisposition of Assistive Technology Use that Constitutes the Matching, Person \& Technology Model. Revista Brasileira de Educação Especial, v. 25, n. 2, p. 189-204, 2019.

CORDEIRO, L. I.; LOPES, T. O.; LIRA, L. E. A. Validação de cartilha educativa para prevenção de HIV/Aids em idosos. Revista Brasileira de Enfermagem, v. 70, n. 4, p. 775-782, 2017.

CUPERTINO, L. H.; SILVA, N. A.; SOUZA, G. T. Avaliação do controle de qualidade empregado na manipulação do anti-hipertensivo enalapril em uma farmácia de Ipatinga-MG. Única Cadernos Acadêmicos, v. 3, n. 1, p. 1-8, 2017.

FERREIRA, A. O. Guia prático de farmácia magistral. 5. ed. São Paulo: Pharmabooks, 2019.

FLANAGAN, T. Potential for pharmaceutical excipients to impact absorption: A mechanistic review for BCS Class 1 and 3 drugs. European Journal of Pharmaceutics and Biopharmaceutics, v. 141, p. 130-138, 2019.

JONES, H. M.; PARROTT, N.; OHLENBUSCH, G. Predicting pharmacokinetic food effects using biorelevant solubility media and physiologically based modelling. Clinical Pharmacokinetics, v. 45, n. 12, p. 1.213-1.226, 2006.

NASCIMENTO, J. F.; SANTANA, E. A.; SILVA JÚNIOR, A. C. S. Descrição de excipientes presentes em medicamentos antimicrobianos de diferentes marcas comerciais. Revista Arquivos Científicos (IMMES), v. 2, n. 1, p. 4-11, 2019.

REKER, D.; BLUM, S. M.; STEIGER, C. Inactive ingredients in oral medications, Science Translational Medicine. v. 11, n. 483, p. 6.753, 2019.

RUMEL, D.; NISHIOKA, S. A.; SANTOS, A. A. M. Drug interchangeability: clinical approach and consumer's point of view. Revista de Saúde Pública, v. 40, n. 5, p. 921-927, 2006.

SILVA, C. M. L.; LIMA, B. S.; CRUZ, E. S. Avaliação da qualidade de cápsulas de losartana potássica manipuladas no município de Lagarto-SE. Scientia Plena, v. 14, n. 7, p. 1-8, 2018.

SILVA, D. A.; LÖBENBERG, R.; DAVIES, N. Are excipients inert? Phenytoin pharmaceutical investigations with new incompatibility insights, Journal of Pharmacy \& Pharmaceutical Sciences, v. 21, n. 1, p. 19-31, 2018.

SOUSA, C. S.; TURRINI, R. N. T. Validação de constructo de tecnologia educativa para pacientes mediante aplicação da técnica Delphi. Acta Paulista de Enfermagem, v. 25, n. 6, p. 990-996, 2012.

VAN DER MERWE, J.; STEENEKAMP, J.; STEYN, D. The role of functional excipients in solid oral dosage forms to overcome poor drug dissolution and bioavailability, Pharmaceutics, v. 12, n. 5, p. 393, 2020.

Editora Unijuí - Revista Contexto \& Saúde - ISSN 2176-7114 - v. 21, n. 43, jul./set. 2021 
VASCONCELOS, T. Y. L.; CANGUSSI, I. M.; MESQUITA, R. J. M. A farmácia clínica no âmbito da farmácia magistral. Journal of Applied Pharmaceutical Science, v. 3, p. 4-6, 2016.

VILLANOVA, J. C. O.; SÁ, V. R. Excipientes: Guia prático para padronização. 2. ed. São Paulo: Pharmabooks, 2009. 